\title{
Absolute Viscosities of Vegetable Oils at Different Temperatures and Shear Rate Range of 64.5 to $4835 \mathrm{~s}^{-1}$
}

\author{
Lemuel M. Diamante and Tianying Lan \\ Department of Wine, Food and Molecular Biosciences, Lincoln University, Lincoln, Christchurch 7647, New Zealand \\ Correspondence should be addressed to Lemuel M. Diamante; lemuel.diamante@lincoln.ac.nz
}

Received 1 May 2014; Revised 15 July 2014; Accepted 17 July 2014; Published 3 August 2014

Academic Editor: Soichiro Nakamura

Copyright ( 2014 L. M. Diamante and T. Lan. This is an open access article distributed under the Creative Commons Attribution License, which permits unrestricted use, distribution, and reproduction in any medium, provided the original work is properly cited.

\begin{abstract}
A study was carried out to determine the effect of higher shear rates ( 64.5 to $4835 \mathrm{~s}^{-1}$ ) on the absolute viscosities of different vegetable oils at different temperatures $\left(26\right.$ to $90^{\circ} \mathrm{C}$ ). The absolute viscosities of the different vegetable oils were determined using a Lamy Viscometer RM100, a rotating viscometer with coaxial cylinder. The torque of each sample at different temperatures was recorded at different shear rates. Based on the rheograms (plot of mean shear stress against shear rate), all of the vegetable oils studied were found to be Newtonian fluids. Rice bran oil was the most viscous $\left(0.0398 \mathrm{~Pa} \cdot \mathrm{s}\right.$ at $\left.38^{\circ} \mathrm{C}\right)$ while walnut oil was the least viscous $\left(0.0296 \mathrm{~Pa} \cdot \mathrm{s}\right.$ at $\left.38^{\circ} \mathrm{C}\right)$ among the oils studied. The higher shear range used did not significantly affect the absolute viscosities of the vegetable oils at the different temperatures. The absolute viscosities of the vegetable oils decreased with increasing temperature and can be fitted with an Arrhenius type relationship. The activation energies for the different vegetable oils ranged from 21 to $30 \mathrm{~kJ} / \mathrm{mole}$. The peanut and safflower oils had the highest and lowest activation energies, respectively. This means that greater energy was needed to effect a viscosity change in the peanut oil.
\end{abstract}

\section{Introduction}

Oils and fats are the essential materials for margarine, shortening, salad oil, and other specialty or tailored products, which have become significant ingredients in food preparation or processing in homes, restaurants, or food manufacturers [1]. The majority of the edible oils and fats produced worldwide annually is derived from plant sources and is referred as vegetable oils [2].

Common commercially-available vegetable oils are canola, corn, olive, peanut, soybean, sunflower, and others $[1,3]$. There are also number of new vegetable oils such as grape seed, rice bran, macadamia nut, and many others [4-6].

Oil viscosity is typically measured and defined in two ways, either based on its absolute viscosity or its kinematic viscosity. The absolute viscosity of oil is its resistance to flow and shear due to internal friction and it is measured with SI units of Pa.s. In contrast, the kinematic viscosity of oil is its resistance to flow and shear due to gravity and it is measured with SI units of $\mathrm{m}^{2} / \mathrm{s}$. The kinematic viscosity of oil can be obtained by dividing the oil absolute viscosity with its corresponding density [7].

It has been well established that temperature has a strong influence on the viscosity of fluids with viscosity generally decreasing with increase in temperature [8]. The Arrhenius model is commonly used to describe the relationship of the temperature dependence on vegetable oil viscosity [9].

The absolute viscosity of fluids is an important property needed in fluid flow and heat transfer unit operations. This includes pumping, flow measurement, heat exchange, sterilization, freezing, and many other operations [7].

A number of studies have already been published on the effect of temperature on the absolute viscosities of vegetable oils [9-13]. However, all of these studies were obtained in a very limited shear rate range of $120 \mathrm{~s}^{-1}$ or lower. The use of higher shear rate range on the vegetable oils might affect their viscosities. There is, therefore, a need to determine the 
TABLE 1: Energy and fat contents and fatty acids composition in different vegetable oils.

\begin{tabular}{|c|c|c|c|c|c|}
\hline \multirow{2}{*}{ Oil } & \multirow{2}{*}{ Energy $(\mathrm{kJ} / 100 \mathrm{~mL})$} & \multirow{2}{*}{ Total fat $(\mathrm{g} / 100 \mathrm{~mL})$} & \multicolumn{3}{|c|}{ Fatty acids (\%) } \\
\hline & & & Saturated & Polyunsaturated & Monounsaturated \\
\hline Avocado (C) & 3370 & 91.0 & 14.3 & 11.0 & 74.7 \\
\hline Canola & 3770 & 92.0 & 6.5 & 35.9 & 57.6 \\
\hline Grape Seed & 3390 & 91.5 & 10.0 & 71.0 & 19.0 \\
\hline Macadamia Nut (C) & 3360 & 91.0 & 16.5 & 2.2 & 81.3 \\
\hline Olive $(\mathrm{C}+\mathrm{R})$ & 3390 & 91.5 & 15.3 & 9.8 & 74.9 \\
\hline Peanut & 3770 & 92.0 & 18.5 & 20.6 & 60.9 \\
\hline Rapeseed (C) & 3700 & 100.0 & 6.8 & 28.2 & 65.2 \\
\hline Rice Bran & 3373 & 91.0 & 22.3 & 35.4 & 42.3 \\
\hline Safflower (C) & 3404 & 92.0 & 10.0 & 73.0 & 17.0 \\
\hline Sesame & 3350 & 90.5 & 16.0 & - & - \\
\hline Soybean & 3770 & 92.0 & 15.2 & 60.9 & 22.8 \\
\hline Sunflower & 3770 & 92.0 & 13.0 & 68.5 & 18.5 \\
\hline Walnut (C) & 3690 & 100.0 & 9.0 & 70.0 & 21.0 \\
\hline
\end{tabular}

C: cold pressed; R: refined.

viscosities of oils over a wider and higher shear rate range (64.5 to $4835 \mathrm{~s}^{-1}$ ) and to evaluate their effect on the oil viscosity.

\section{Materials and Methods}

2.1. Materials. The different vegetable oils were purchased from local supermarkets and specialty shops. These vegetable oils include avocado oil (cold pressed), canola oil, grape seed oil, macadamia nut oil (cold pressed), olive oil (mixture of cold pressed and refined), peanut oil, rapeseed oil (cold pressed), rice bran oil, safflower oil (cold pressed), sesame oil, soybean oil, sunflower oil, and walnut oil (cold pressed). All oils were stored at room temperature (around $20^{\circ} \mathrm{C}$ ) and in a dark place before analysis. Table 1 shows the energy and fat contents, as well as the fatty acids composition of the different oils used. The sesame seed oil showed only total fat content and saturated fatty acids on its label. The vegetable oils used have energy contents ranging from 3350 to $3770 \mathrm{~kJ} / 100 \mathrm{~mL}$ and the total fat contents ranged from 90.5 to $100 \mathrm{~g} / 100 \mathrm{~mL}$.

2.2. Experimental Methods. The absolute viscosities of the different vegetable oils were determined using a Lamy Viscometer RM100 (Lamy, France), a rotating viscometer with coaxial cylinder. Approximately $25 \mathrm{~mL}$ of oil was placed in the Tube DIN 1 outer cylinder, and then the bob MK Din9 was inserted. The radius of the tube $\left(R_{a}\right)$ is $16.25 \mathrm{~mm}$ and the radius of the bob is $\left(R_{i}\right) 15.5 \mathrm{~mm}$. The length of the bob is $54 \mathrm{~mm}$. The correct mode was set for the appropriate measuring system (MS 19) and the measurement time was fixed at 60 seconds. A circulatory water bath was set at $26 \pm$ $1^{\circ} \mathrm{C}, 30 \pm 1^{\circ} \mathrm{C}, 38 \pm 1^{\circ} \mathrm{C}, 40 \pm 1^{\circ} \mathrm{C}, 50 \pm 1^{\circ} \mathrm{C}, 70 \pm 1^{\circ} \mathrm{C}$, and $90 \pm 1^{\circ} \mathrm{C}$ to maintain a constant temperature for the viscosity measurement. The torque of each sample at the different temperatures was recorded at a range of shear rate $(\gamma)$ from 64.5 to $4835 \mathrm{~s}^{-1}$. All viscometric measurements of the samples were carried out in triplicate. Every replicate was run twice; the shear rate in the first run was increased from 64.5 to $4835 \mathrm{~s}^{-1}$ and the shear rate in the second run was decreased from 4835 to $64.5 \mathrm{~s}^{-1}$. The mean torque value of the two runs was recorded for each replicate at a given shear rate. The shear stress was obtained from

$$
\tau=\frac{1+\delta^{2}}{2 \delta^{2}} * \frac{M}{2 \pi L R_{i}^{2}},
$$

where $\tau=$ shear stress $(\mathrm{Pa}), \delta=$ ratio of $R_{a}$ to $R_{i}, R_{a}=$ radius of the tube (m), $R_{i}=$ radius of the bob $(\mathrm{m}), L=$ length of the bob $(\mathrm{m})$, and $M=$ torque reading $(\mathrm{N} \cdot \mathrm{m})$.

The absolute viscosity of the oils was obtained from the slope of the linear regression of shear stress $(\tau)$ against shear rate $(\gamma)$ based on the Newton equation [14] as shown below:

$$
\tau=I+\mu \gamma,
$$

where $I=$ intercept of the linear regression which should be approximately zero and $\mu=$ absolute viscosity (Pa.s)

2.3. Temperature Dependency of Absolute Viscosity. The effect of temperature on the absolute viscosity follows the Arrhenius type equation [7], which can be used to calculate the activation energy:

$$
\mu=\mu_{o} \exp \left(\frac{E_{a}}{\mathrm{RT}}\right) .
$$

Equation (3) can written in a regression form as shown below:

$$
\ln \mu=\ln \mu_{o}+\left(\frac{E_{a}}{R_{g}}\right)\left(\frac{1}{T_{K}}\right),
$$

where $\mu=$ consistency coefficient (Pa.s), $\mu_{o}=$ preexponential constant $(\mathrm{Pa} \cdot \mathrm{s}), E_{a}=$ activation energy $(\mathrm{J} / \mathrm{mol}), R_{g}=$ gas constant $(8.314 \mathrm{~J} /(\mathrm{mol} \cdot \mathrm{K}))$, and $T_{K}=$ absolute temperature (K).

The activation energy can be obtained from the slope of the regression equation. 
2.4. Data Analyses. Office Excel 2013 software was used to carry out the linear regressions for obtaining the absolute viscosity and activation energy of the oils. The mean absolute viscosity values of the different oils at different temperatures together with standard errors were obtained.

The mean relative percentage error (MRPE) was used to evaluate the adequacy of the derived Arrhenius type equations in predicting the absolute viscosity of the different vegetable oils at different temperatures, as outlined in Diamante et al. [15].

\section{Results and Discussion}

3.1. Rheograms of Different Vegetable Oils. The vegetable oils analysed were derived from the following plant materials: cereal (rice bran), flower seeds (safflower and sunflower), fruit pulp (avocado), fruit seed (grape seed), pod seeds (canola, rapeseed, sesame seed, and soybean), whole fruit (olive), and nuts (peanut, macadamia, and walnut). Figure 1 shows the rheograms of representative vegetable oils at different temperatures with the lowest (walnut oil) and highest (rice bran oil) shear stresses. The rheograms for the other vegetable oils behaved the same and fell within the ranges of the shear stresses of walnut and rice bran oils. The results show that the shear stress increases with shear rate for all vegetable oils and at all temperatures. It must be noted that all of the plots have straight lines which strongly suggested that all vegetable oils were Newtonian fluids [14]. The same observation was also concluded for the other vegetable oils not shown here. In addition, the shear stress decreases with increasing temperature at constant shear rate. This was due to the higher thermal movement among the oil molecules, reducing the intermolecular forces, making the flow among them easier, and reducing viscosity [10].

3.2. Absolute Viscosities of Different Vegetable Oils. The absolute viscosities of the measured vegetable oils are summarized in Table 2. The range of the coefficient of determination $\left(r^{2}\right)$ for each oil and temperature are also shown. The $r^{2}$ values for all vegetable oils and temperatures were very high (above 0.99) indicating that all experimental data fell on straight lines. The rice bran oil gave consistently high absolute viscosities while the walnut oil gave consistently low viscosities at all temperatures compared with the other vegetable oils. All of the viscosity values of the vegetable oils decrease with increasing temperature. This phenomenon was explained earlier in the previous section. All of the standard errors were very low, which means that the viscosity values obtained were very stable. The same effect of temperature on the absolute viscosities of the vegetable oils was also observed by Fasina and Colley [9], Santos et al. [10], Abramovič and Klofutar [11], Steffe [12], and Noureddini et al. [13] for various vegetable oils at different temperatures.

Table 3 shows the experimental and published $[9,12,13]$ absolute viscosities of different vegetable oils at different temperatures. The results show that most of the experimental values of the different vegetable oils studied were comparable with the published values at the same temperatures. The



$$
\begin{array}{ll}
-26^{\circ} \mathrm{C} \text { walnut oil } & \diamond 26^{\circ} \mathrm{C} \text { rice bran oil } \\
-38^{\circ} \mathrm{C} \text { walnut oil } & \circ 38^{\circ} \mathrm{C} \text { rice bran oil } \\
\triangle 50^{\circ} \mathrm{C} \text { walunt oil } & \triangle 50^{\circ} \mathrm{C} \text { rice bran oil }
\end{array}
$$

FIGURE 1: Rheograms of representative vegetable oils at different temperatures with the lowest (-walnut oil) and highest (. . .rice bran oil) shear stresses.

experimental absolute viscosities of some vegetable oils were also comparable with the published data even at different temperatures when taking into account the effect of temperature on the viscosity of the oil. Generally, the experimental viscosity of a specific oil and temperature was lower compared with the published data at lower temperature which coincides with the theory. The results suggested that the higher shear range used did not affect the absolute viscosities of the vegetable oils at different temperatures.

The results show that among the vegetable oils studied, rice bran oil $\left(0.0398 \mathrm{~Pa} \cdot \mathrm{s}\right.$ at $\left.38^{\circ} \mathrm{C}\right)$ was the most viscous followed closely by the macadamia nut oil (0.0394 Pa.s at $38^{\circ} \mathrm{C}$ ) while the walnut oil $\left(0.0296 \mathrm{~Pa} \cdot \mathrm{s}\right.$ at $\left.38^{\circ} \mathrm{C}\right)$ was the least viscous and followed closely by the safflower oil (0.0299 Pa.s at $38^{\circ} \mathrm{C}$ ). Generally, the same trend was also observed at other temperatures. The rest of the vegetable oils has viscosities that fell within the range of the rice bran and walnut oils with viscosities from 0.0311 to $0.0380 \mathrm{~Pa} \cdot \mathrm{s}$ at $38^{\circ} \mathrm{C}$.

Examining Table 1, it was observed that when the amount of saturated fatty acids in the vegetable oil was above $16 \%$, the absolute viscosity was higher. However, there was no correlation with absolute viscosity when the saturated fatty acids were below $16 \%$. This is in agreement with the results by Kim et al. [16] which also found the same trend for the different vegetable oils that they studied.

3.3. Temperature Dependency of Absolute Viscosity. The absolute viscosities of the different vegetable oils were related to temperature using an Arrhenius type relationship using (4) and their slopes, intercepts, and coefficients of determination were determined.

The slope of the regression was used in deriving the activation energy for each vegetable oil. The $r^{2}$ values of the Arrhenius regressions and the derived activation energies of the different vegetable oils as well as the published values [9] for activation energies of selected vegetable oils are shown in Table 4. 
TABLE 2: Mean and standard error for absolute viscosity of the different vegetable oils at different temperatures for a shear rate range of 64.5 to $4835 \mathrm{~s}^{-1}$ and the coefficients of determination $\left(r^{2}\right)$ of linear regression for the shear stress and shear rate data.

\begin{tabular}{|c|c|c|c|}
\hline Oil & Temperature $\left({ }^{\circ} \mathrm{C}\right)$ & Absolute viscosity $(\mathrm{Pa} \cdot \mathrm{s})$ & $r^{2}$ \\
\hline \multirow{3}{*}{ Avocado } & 26 & $0.0576 \pm 0.0002$ & $0.9996-1.0000$ \\
\hline & 38 & $0.0364 \pm 0.0003$ & $0.9996-1.0000$ \\
\hline & 50 & $0.0287 \pm 0.0006$ & 0.9997-1.0000 \\
\hline \multirow{3}{*}{ Canola } & 30 & $0.0462 \pm 0.0005$ & $0.9997-1.0000$ \\
\hline & 50 & $0.0245 \pm 0.0002$ & 0.9993-0.9998 \\
\hline & 90 & $0.0108 \pm 0.0004$ & 0.9952-0.9982 \\
\hline \multirow{3}{*}{ Grape seed } & 26 & $0.0466 \pm 0.0003$ & $0.9997-1.0000$ \\
\hline & 38 & $0.0311 \pm 0.0001$ & 0.9999-1.0000 \\
\hline & 50 & $0.0227 \pm 0.0000$ & 0.9995-1.0000 \\
\hline \multirow{3}{*}{ Macadamia nut } & 26 & $0.0583 \pm 0.0003$ & 0.9998-0.9998 \\
\hline & 38 & $0.0394 \pm 0.0002$ & $0.9816-1.0000$ \\
\hline & 50 & $0.0272 \pm 0.0012$ & 0.9997-0.9998 \\
\hline \multirow{4}{*}{ Olive } & 26 & $0.0562 \pm 0.0003$ & $0.9997-1.0000$ \\
\hline & 38 & $0.0341 \pm 0.0005$ & 0.9994-1.0000 \\
\hline & 50 & $0.0261 \pm 0.0003$ & 0.9997-1.0000 \\
\hline & 70 & $0.0157 \pm 0.0001$ & 0.9990-0.9992 \\
\hline \multirow{3}{*}{ Peanut } & 26 & $0.0574 \pm 0.0007$ & $0.9992-0.9996$ \\
\hline & 38 & $0.0380 \pm 0.0002$ & $0.9999-1.0000$ \\
\hline & 54 & $0.0236 \pm 0.0003$ & 0.9998-0.9999 \\
\hline \multirow{3}{*}{ Rapeseed } & 26 & $0.0592 \pm 0.0011$ & 0.9998-0.9999 \\
\hline & 38 & $0.0376 \pm 0.0001$ & $1.0000-1.0000$ \\
\hline & 50 & $0.0305 \pm 0.0001$ & 0.9972-0.9998 \\
\hline \multirow{3}{*}{ Rice bran } & 26 & $0.0593 \pm 0.0006$ & 0.9996-0.9997 \\
\hline & 38 & $0.0398 \pm 0.0001$ & 0.9999-1.0000 \\
\hline & 50 & $0.0280 \pm 0.0000$ & 0.9997-0.9999 \\
\hline \multirow{3}{*}{ Safflower } & 26 & $0.0445 \pm 0.0003$ & $0.9998-1.0000$ \\
\hline & 38 & $0.0299 \pm 0.0000$ & $0.9989-1.0000$ \\
\hline & 50 & $0.0239 \pm 0.0005$ & 0.9992-0.9996 \\
\hline \multirow{3}{*}{ Sesame } & 26 & $0.0525 \pm 0.0007$ & 0.9999-0.9999 \\
\hline & 38 & $0.0351 \pm 0.0002$ & $1.0000-1.0000$ \\
\hline & 50 & $0.0251 \pm 0.0002$ & 0.9995-0.9999 \\
\hline \multirow{3}{*}{ Soybean } & 30 & $0.0405 \pm 0.0003$ & 0.9993-1.0000 \\
\hline & 50 & $0.0232 \pm 0.0001$ & 0.9996-0.9998 \\
\hline & 90 & $0.0098 \pm 0.0003$ & 0.9905-0.9980 \\
\hline \multirow{3}{*}{ Sunflower } & 26 & $0.0488 \pm 0.0002$ & 0.9998-0.9999 \\
\hline & 38 & $0.0323 \pm 0.0005$ & 0.9998-0.9999 \\
\hline & 50 & $0.0234 \pm 0.0001$ & 0.9975-0.9993 \\
\hline \multirow{3}{*}{ Walnut } & 26 & $0.0429 \pm 0.0003$ & 0.9998-0.9999 \\
\hline & 38 & $0.0296 \pm 0.0002$ & $0.9989-1.0000$ \\
\hline & 50 & $0.0212 \pm 0.0001$ & 0.9975-0.9972 \\
\hline
\end{tabular}

The $r^{2}$ values for all vegetable oils were high (above 0.96) suggesting that the Arrhenius type equation can be used to relate the viscosity with temperature. The derived Arrhenius type equations were further evaluated for vegetable oils with $r^{2}$ values of lower than 0.99 using the mean relative percentage error (MRPE) and the results are shown in parentheses next to the $r^{2}$ values in Table 4 . It is understood that equations with $r^{2}$ values greater than 0.99 will have lower MRPE values. The results show that the selected vegetable oils with $r^{2}$ values lower than 0.99 have MRPE values of $5 \%$ or less. For most engineering applications, MRPE values of $10 \%$ or lower are acceptable.

The experimental activation energies for the absolute viscosities of the different vegetable oils ranged from 21 to $30 \mathrm{~kJ} / \mathrm{mole}$. The peanut and safflower oils had the highest and lowest activation energies, respectively. This means that greater energy was needed to effect a viscosity change in the peanut oil. 
TABlE 3: Absolute viscosities of the different vegetable oils at different temperatures (experimental and published).

\begin{tabular}{|c|c|c|c|c|c|}
\hline \multirow{2}{*}{ Oil } & \multirow{2}{*}{ Temperature $\left({ }^{\circ} \mathrm{C}\right)$} & \multicolumn{4}{|c|}{ Absolute viscosity $(\mathrm{Pa} \cdot \mathrm{s})$} \\
\hline & & Experimental $^{*}$ & Published Ref1 & Published Ref2 & Published Ref3 \\
\hline \multirow{2}{*}{ Olive } & 40 & 0.0341 & 0.0363 & & $0.0463\left(35^{\circ} \mathrm{C}\right)$ \\
\hline & 70 & 0.0157 & 0.0124 & & $0.0181\left(65^{\circ} \mathrm{C}\right)$ \\
\hline \multirow{3}{*}{ Peanut } & 26 & 0.0574 & $0.0565\left(21^{\circ} \mathrm{C}\right)$ & & \\
\hline & 38 & 0.0380 & 0.0387 & & $0.0456\left(35^{\circ} \mathrm{C}\right)$ \\
\hline & 54 & 0.0236 & 0.0268 & & $0.0275\left(50^{\circ} \mathrm{C}\right)$ \\
\hline \multirow{2}{*}{ Rapeseed } & 38 & 0.0376 & & 0.0449 & \\
\hline & 50 & 0.0305 & & $0.0303\left(49^{\circ} \mathrm{C}\right)$ & \\
\hline \multirow{2}{*}{ Safflower } & 26 & 0.0445 & $0.0522\left(25^{\circ} \mathrm{C}\right)$ & & \\
\hline & 38 & 0.0299 & 0.0286 & & $0.0353\left(35^{\circ} \mathrm{C}\right)$ \\
\hline \multirow{2}{*}{ Sesame } & 38 & 0.0351 & 0.0324 & & $0.0411\left(35^{\circ} \mathrm{C}\right)$ \\
\hline & 50 & 0.0251 & & & 0.0248 \\
\hline \multirow{3}{*}{ Soybean } & 30 & 0.0405 & 0.0406 & & $0.0386\left(35^{\circ} \mathrm{C}\right)$ \\
\hline & 50 & 0.0232 & 0.0206 & $0.0233\left(49^{\circ} \mathrm{C}\right)$ & 0.0236 \\
\hline & 90 & 0.0098 & 0.0078 & $0.0095\left(82^{\circ} \mathrm{C}\right)$ & $0.0087\left(95^{\circ} \mathrm{C}\right)$ \\
\hline \multirow{2}{*}{ Sunflower } & 38 & 0.0323 & 0.0311 & & \\
\hline & 50 & 0.0234 & & & 0.0250 \\
\hline
\end{tabular}

* Mean of 3 measurements; Ref1: Steffe [12]; Ref2: Noureddini et al. [13]; Ref3: Fasina and Colley [9].

TABLE 4: Coefficient of determination of the Arrhenius regression and activation energy for the absolute viscosity of the different vegetable oils (experimental and published).

\begin{tabular}{|c|c|c|c|c|}
\hline \multirow{2}{*}{ Oil } & \multirow{2}{*}{ Coefficient of determination } & \multicolumn{3}{|c|}{ Activation energy $(\mathrm{kJ} / \mathrm{mol})$} \\
\hline & & Experimental & Published* & \% Difference \\
\hline Avocado & $0.9617(4.0 \%)^{\#}$ & 22.28 & & \\
\hline Canola & 0.9950 & 21.95 & 23.20 & 5.69 \\
\hline Grape seed & 0.9976 & 24.11 & 21.31 & 15.76 \\
\hline Macadamia nut & 1.0000 & 25.53 & & \\
\hline Olive & 0.9976 & 24.57 & 24.63 & 0.24 \\
\hline Peanut & $0.9878(5.0 \%)^{\#}$ & 29.69 & 24.45 & 17.65 \\
\hline Rapeseed & $0.9652(4.9 \%)^{\#}$ & 22.30 & & \\
\hline Rice Bran & 0.9998 & 25.14 & & \\
\hline Safflower & $0.9812(3.3 \%)^{\#}$ & 20.88 & 21.76 & 4.21 \\
\hline Sesame & 0.9991 & 24.73 & 23.38 & 5.46 \\
\hline Soybean & 0.9996 & 21.58 & 22.95 & 6.35 \\
\hline Sunflower & 0.9976 & 24.64 & 23.40 & 5.03 \\
\hline Walnut & 0.9991 & 24.73 & 21.47 & 13.18 \\
\hline
\end{tabular}

* Fasina and Colley [9]; ${ }^{\#}$ mean relative percentage error.

Almost all of the experimental values of the different vegetable oils were comparable with the published data of Fasina and Colley [9] except for the grape seed, peanut, and walnut oils which have percentage differences ranging from $13-17 \%$. The variation observed for these vegetable oils was probably due to the method of preparation of the oils used in the study (cold pressed, hot pressed, and solvent extracted). Liu et al. [17] showed that the extraction process affected the rheological properties of rapeseed oils.

\section{Conclusions}

Based on the rheograms, all of the vegetable oils studied were found to be Newtonian fluids. Rice bran oil was the most viscous followed closely by macadamia nut oil while walnut oil was the least viscous and followed by grape seed oil among the oils studied. The higher shear range used $\left(64.5\right.$ to $4835 \mathrm{~s}^{-1}$ ) did not significantly affect the absolute viscosities of the vegetable oils at the different temperatures. The absolute viscosities of the vegetable oils decrease with increasing temperature and can be fitted with an Arrhenius type relationship. The activation energy values for the absolute viscosities of the different vegetable oils ranged from 21 to $30 \mathrm{~kJ} / \mathrm{mole}$. The peanut and safflower oils had the highest and lowest activation energies, respectively.

\section{Conflict of Interests}

The authors declare that there is no conflict of interests regarding the publication of this paper. 


\section{References}

[1] R. D. O'Brien, Fat and Oil Formulating and Processing for Applications, CRC Press, Boca Raton, Fla, USA, 2009.

[2] W. Hamm and R. J. Hamilton, Edible Oil Processing, CRC Press, New York, NY, USA, 2000.

[3] E. Nwokolo and J. Smartt, Food and Feed from Legumes and Oilseeds, Chapman \& Hall, London, UK, 1996.

[4] N. G. Baydar and M. Akkurt, "Oil content and oil quality properties of some grape seeds," Turkish Journal of Agriculture and Forestry, vol. 25, no. 3, pp. 163-168, 2001.

[5] K. Tomita, S. Machmudah, Wahyudiono et al., "Extraction of rice bran oil by supercritical carbon dioxide and solubility consideration," Separation and Purification Technology, vol. 125, pp. 319-325, 2014.

[6] F. A. Silva, A. Marsaioli Jr., G. J. Maximo, M. A. A. P. Silva, and L. A. G. Gonçalves, "Microwave assisted drying of macadamia nuts," Journal of Food Engineering, vol. 77, no. 3, pp. 550-558, 2006.

[7] R. P. Singh and D. R. Heldman, Introduction to Food Engineering, Academic Press, London, UK, 2001.

[8] M. A. Rao, Rheology of Fluid and Semifluid Foods: Principles and Applications, Aspen Publication, Gaithersburg, Md, USA, 1999.

[9] O. O. Fasina and Z. Colley, "Viscosity and specific heat of vegetable oils as a function of temperature: $35^{\circ} \mathrm{C}$ to $180^{\circ} \mathrm{C}$," International Journal of Food Properties, vol. 11, no. 4, pp. 738746, 2008.

[10] J. C. O. Santos, I. M. G. Santos, and A. G. Souza, "Effect of heating and cooling on rheological parameters of edible vegetable oils," Journal of Food Engineering, vol. 67, no. 4, pp. 401-405, 2005.

[11] H. Abramovič and C. Klofutar, "The temperature dependence of dynamic viscosity for some vegetable oils," Acta Chimica Slovenica, vol. 45, no. 1, pp. 69-77, 1998.

[12] J. F. Steffe, Rheological Methods in Food Process Engineering, Freeman Press, East Lansing, Mich, USA, 1992.

[13] H. Noureddini, B. C. Teoh, and L. Davis Clements, "Viscosities of vegetable oils and fatty acids," Journal of the American Oil Chemists Society, vol. 69, pp. 1189-1191, 1992.

[14] R. L. Earle, Unit Operations in Food Processing, NZIFST, 1983.

[15] L. M. Diamante, R. Ihns, G. P. Savage, and L. Vanhanen, "A new mathematical model for thin layer drying of fruits," International Journal of Food Science and Technology, vol. 45, no. 9, pp. 1956-1962, 2010.

[16] J. Kim, D. N. Kim, S. H. Lee, S. Yoo, and S. Lee, "Correlation of fatty acid composition of vegetable oils with rheological behaviour and oil uptake," Food Chemistry, vol. 118, no. 2, pp. 398-402, 2010.

[17] C. Liu, M. Yang, and F. Huang, "Influence of extraction processing on rheological properties of rapeseed oils," Journal of the American Oil Chemists' Society, vol. 89, no. 1, pp. 73-78, 2012. 

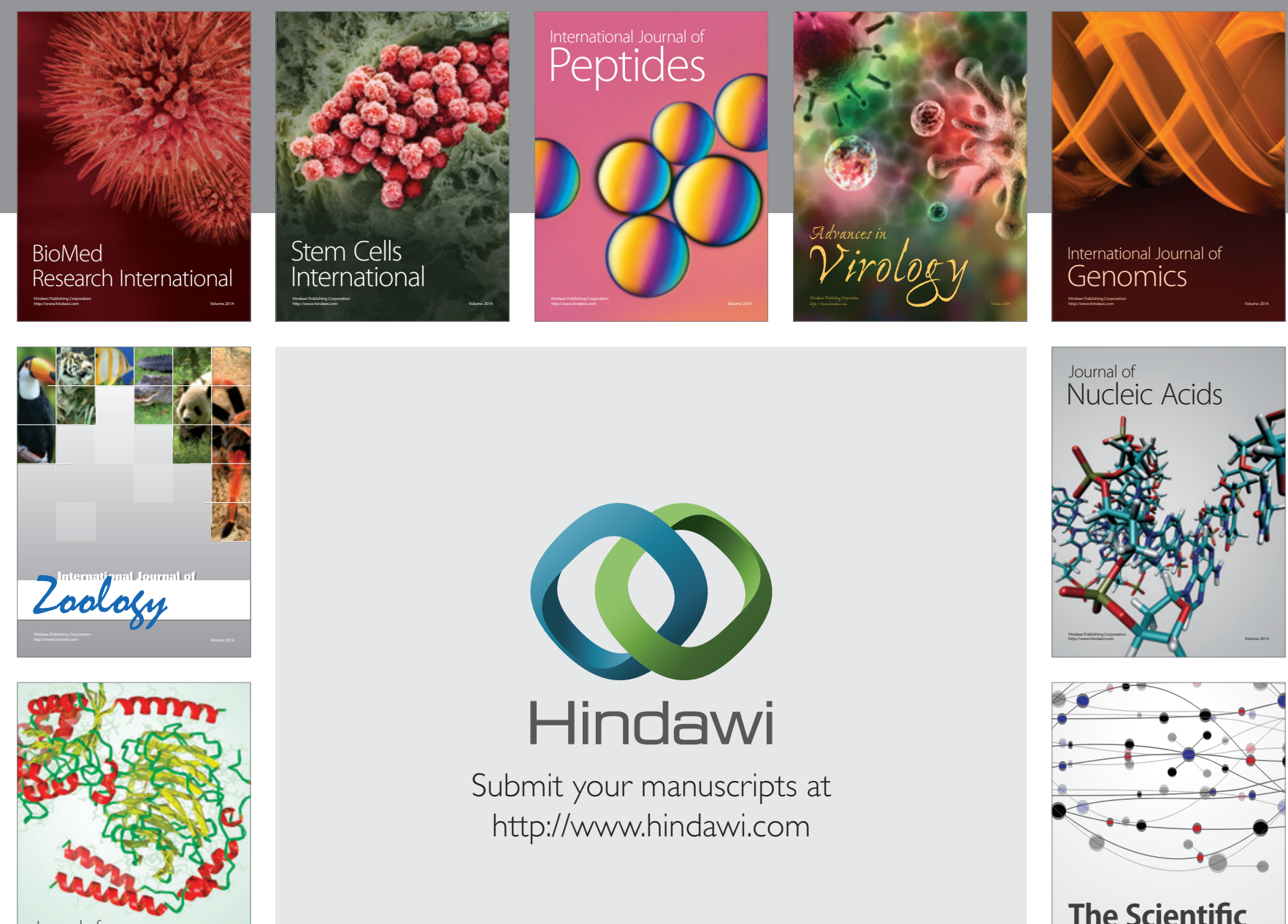

Submit your manuscripts at

http://www.hindawi.com

Journal of
Signal Transduction
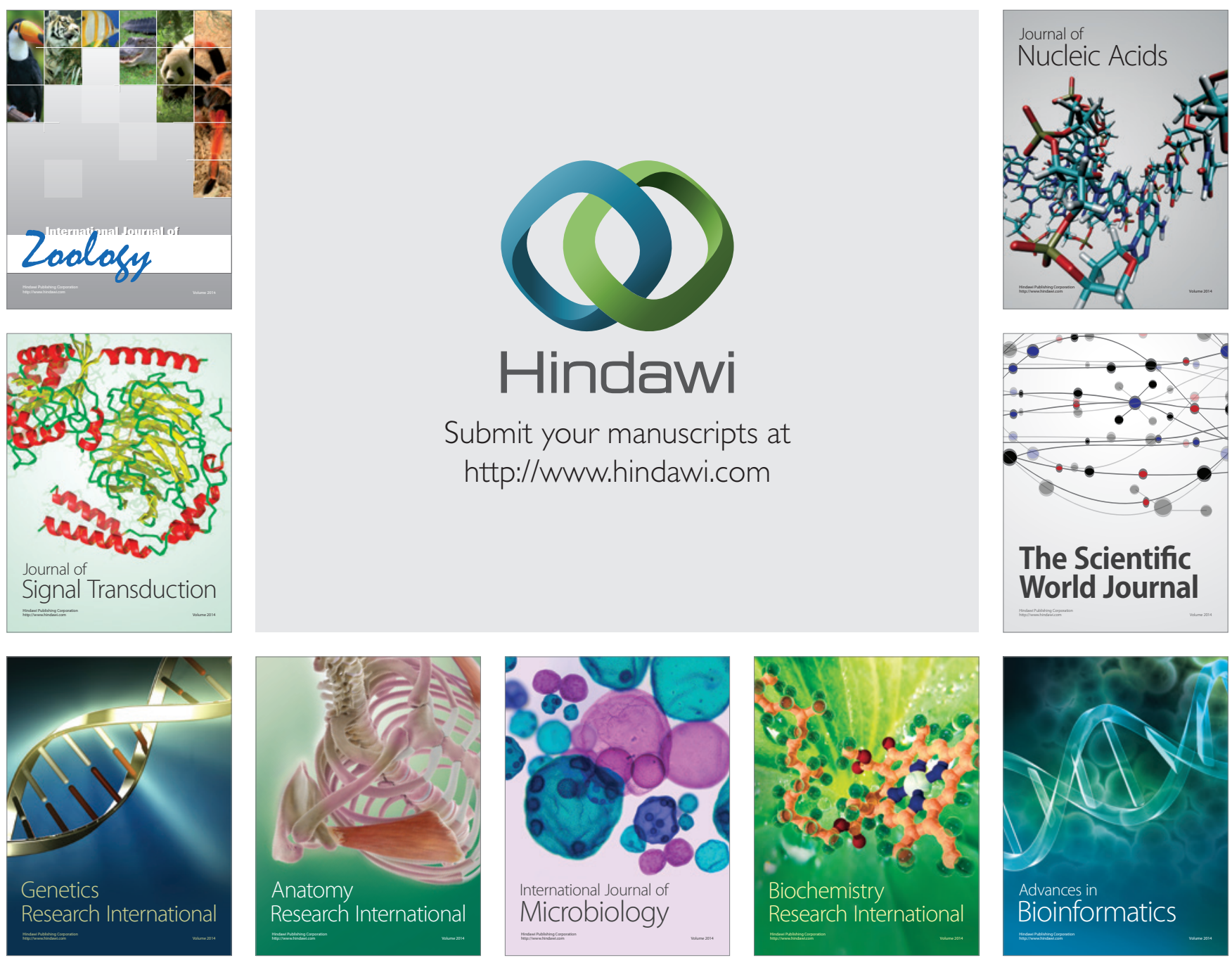

The Scientific World Journal
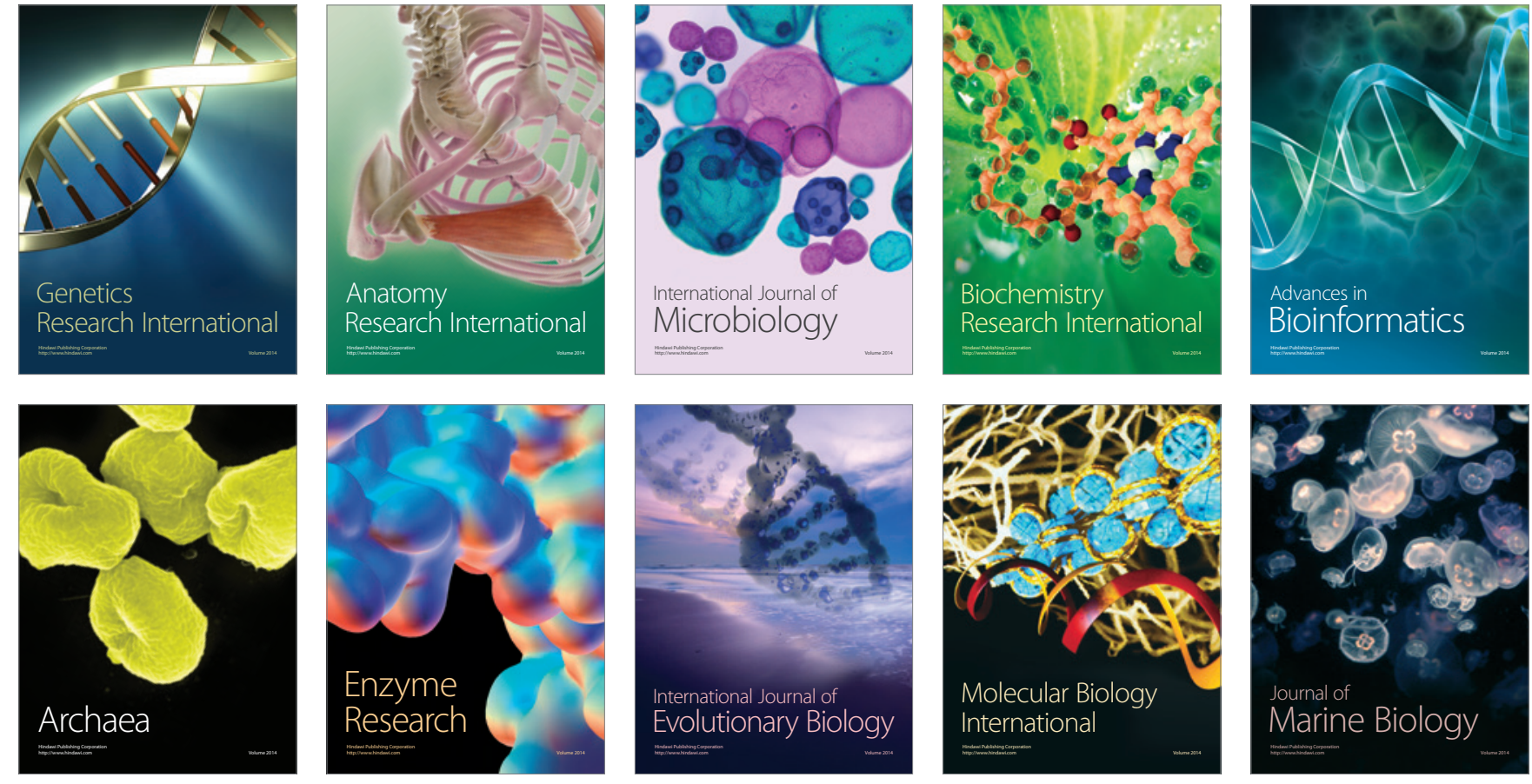